Dr Kasturi Behari-Leak

University of Cape Town

Ms Natalie le Roux

University of Cape Town

Corresponding author

natalie.leroux@uct.ac.za

DOI: $h t t p: / / d x . d o i$.

org/10.18820/2519593X/pie.

V36i1.3

ISSN 0258-2236

e-ISSN 2519-593X

Perspectives in Education

2018 36(1): 30-43

(c) UVIUFS

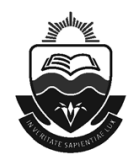

\section{Between a rock and a hard place, third space practitioners exercise agency}

\begin{abstract}
Academics as well as educational and academic development practitioners often find themselves in an ambiguous space in which personal and professional transformation can take place. Moving constantly between contexts and cultural learning environments at the university, these practitioners inhabit a strange, in-between space between mainstream academic support work, leadership and advocacy and other roles at the periphery.

This space known as the third space from which other positions emerge, displaces the histories that constitute it and sets up new structures of authority, practice and discourses which are not always congruent with the university at large. This paper critically reflects on the experiences and insights of academics in a specific professional development course for new academics.
\end{abstract}

Using a critical discourse analysis of in-depth, semi-structured narrative interviews, the authors explore the journey of new academic practitioners as they exercise their agency to carve out a hybrid identity in the third space across institutional boundaries.

While resistance and struggle are challenging aspects of third space work, these constitute legitimate processes of identity construction and socialisation through contestation of traditional roles at the university. This paper interrogates the university's role in creating and sustaining enabling institutional conditions so that academics can work in creative, responsive and relevant ways in a changing higher education landscape.

Keywords: Third space, professional development, new academics, agency

\section{Introduction}

With the expansion and massification of higher education, access has been opened up to students from different political, economic and social backgrounds (Bassnett, 2005). This diversity includes a large proportion of students who are 'differently-prepared' for university study, placing new demands on the role of academics (HESA, 2011) in the classroom. This complexity also manifests in the recruitment and appointment of professional, academic, administrative and support staff (Whitchurch, 2008) with increased workloads who have to juggle a vast array of roles such as research, teaching, administration and fund-raising. Universities' increasing trend towards managerialism and corporatism (Beck \& Young, 2005) has led to recruiting 
and employing new academics with a wide range of demonstrable skills that supersede the traditional role of the research-driven, middle-aged male (Reay, 2004). The contemporary university with its multiple institutional identities and purposes now requires academics with a mixed set of specific skills who can work out of the proverbial 'box'.

As the 'new' university ushers in new institutional projects, new ways of soliciting funding and new methods of assurance, academics' lives become more nuanced and differentiated (Clegg, 2008). Yet in many cases, the structural configuration at the university remains intact, with traditional arrangements far from apace with broader social changes. This tension is pronounced when academic job advertisements and descriptions require a 'skills-set' that is often at odds with the actual demands of the roles when incumbents enact them.

Professionals (administrative, support and non-academic staff) for example, are 'silent workers' in academics' research projects and remain invisible (Szekeres, 2004). Likewise, academics who are now doing a range of non-academic tasks including administrative work (Cain \& Hewitt, 2004: 89) must show leadership skills, gain management experience, and liaise with funders and sponsors on various projects; all of which might better be described as 'professional' work. Academics working in this field are referred to as academic staff developers or professional development practitioners as opposed to academic developers, who work mainly with students. More and more, academics and professionals find themselves in an "in-between", hybrid space that shares attributes of the former traditional roles and identities ascribed by the university.

Given the complexity of the current landscape, it is not surprising that new academics who enter higher education from varied points undergo a huge shift in identity to function as effective practitioners. This paper explores the ways in which new academics struggle with challenges of placement, belonging, purpose and self-worth as they come to terms with changing identities and roles and emerging responsibilities. In this struggle, incumbents embrace new understandings of what it means to be a professional or an academic in current times and one might argue that the university has an obligation to bring these substantively new voices into the conversation (Muller \& Druin, 2012).

This study critically reflects on the experiences and insights of academics and professional development practitioners on a customised professional development course for induction of new academics at a research-intensive university. It explores the concept of hybridity of roles and identities in an emerging field known as the third space (Bhabha, 1994; Whitchurch, $2008,2013)$ to see if there are opportunities for professional development practitioners to grapple with the shifts and changes in traditional university practices. It also explores the emergent implications for new academics who are caught 'between a rock and a hard place' in the academy. As the title of the article suggests, working in the third space often means contending with a series of constraints and challenges that emerge when traditional university job descriptions do not match or align with actual job realities in spaces of practice. These challenges are often experienced as uneasy, difficult and troublesome especially for new academics who are finding their feet. However, even in this challenging space, academics can find their voices and exercise their agency in optimistic and positive ways, especially, as this article suggests, if they are inducted into the academy in thoughtful and deliberate ways. 


\section{Professional development programmes for new academics}

Induction programmes are traditionally conceptualised as ways to enculturate new academics into the university's ways of being (Barnett, 2000). In current times, however, induction cannot serve merely as an 'assimilation' vehicle through which new academics acquire the viewpoints, attitudes and definitions of already established and more experienced people or groups (Trowler \& Knight, 2000). Assimilation models of induction do not enable academics to engage critically with their contextual complexities (Leibowitz, Bozalek, van Schalkwyk \& Winberg, 2014) or to gain insights into the deeper socio-cultural issues at play at the university and in the sector (Mathieson, 2011). Professional development, also known as academic staff development, is aimed at developing the professional practices of academics in their teaching and research roles in the academy, and as such requires attention to a host of environmental and contextual factors (Leibowitz et al., 2014). One-size-fits-all programmes cannot assume that academics will respond in anticipated ways to the content presented or comply with constraining situations (Connors, 2012). When new academics do not fit neatly into the university's designated boxes, they are bound to react in individual ways to problems thrown at them (Archer, 2000). There is therefore increased attention to the need for institutional professional development programmes to induct new academics in ways that ease their transition into the complex HE context (Behari-Leak, 2017; Quinn \& Vorster, 2012).

The New Academics Practitioners' Programme (NAPP) cited in this study is an example of a generic professional development programme for new, full time academics with not more than 5 years' experience in higher education. 'New' is often conflated with 'young', with interesting discursive consequences for new academics regarding how they are received by different stakeholders. The NAPP is intentionally designed to induct new academics to the structural opportunities and cultural nuances by engaging them in critical dialogues about what it means to be a new academic in higher education today. In other words, the focus of the programme is on strengthening new academic agency as they find a place of belonging at the university. To this end, the programme consists of core modules on teaching, learning, assessment, research, management and leadership, and is supported by a range of electives such as community building, challenges of transformation and decolonisation, teaching with technology, online learning and student challenges, with the non-specificity that usually underpins institutional offerings of this nature.

When three new research academics from the educational development unit at the university sought placement on the NAPP, their specific needs could not be catered for because they were employed as "academic lecturers" but were not involved in any form of teaching. Their main function was to develop literacy tests and to translate the diagnostic information from national tests into useable information for stakeholders. Their roles involved data analysis, report writing and dissemination of statistical and other information. The challenge arose when the institutionally ascribed appraisal process did not align with their job description. To complicate matters, while their roles did not carry the full responsibility of the 'academic role', i.e. teaching, they were evaluated using the same criteria as academics who teach. This was a huge source of discomfort and marked their first level of contestation registered by them when they signed up for the NAPP. This led to the creation of a customised offering of professional development. 


\section{The "customised" NAPP offering}

The decision to offer the group a customised programme was based in part on the opportunity it provided for the NAPP professional development team to observe how these new agents exercised their agency within social and cultural contexts (Archer, 2000) at the university. It was also to engage with 'making and re-making their identities' to establish themselves in their new environment and culture (Trowler \& Knight, 2000: 34).

The curriculum for the customised NAPP was derived from suggestions from the academics themselves, underpinned by a strong reflective practitioner model of induction (Brookfield, 1995) proffered by the NAPP team. It was convened over a semester of weekly seminar-type engagements but even before it started, there was a sense these were unchartered waters. It was a new space that required a robust energy, commitment and involvement from academics and the Professional Development Practitioners (PDP) alike.

When the reflective process began, it became clear that elements of third space theory were being invoked and enacted in the customised NAPP. To improve understanding of the extent to which professional development programmes could respond to specific academics' needs, third space theory is used as a theoretical framework to inform this study. In the following section, some of the central tenets of third space theory are examined in relation to the customised induction model being discussed.

\section{The third space of professional development}

Homi Bhabha (1994) first developed the concept of third space as a metaphor for the space in which two cultures meet. Bhabha (1994) identified a dynamic, "in-between space" in which cultural translation takes place. When migrants left their homes ( $1^{\text {st }}$ place) to settle in a foreign land $\left(2^{\text {nd }}\right.$ place $)$, they defied the notion that a pure, homogeneous cultural place exists. The new 'in-between' space shares attributes of both spaces (Saudelli, 2012) and is a generative space where academics combine diverse knowledges into new insights and plans for action (Bhabha, 1990).

The concept of "spatiality" (Soja,1989), which is critical to third space theory in academic institutions, includes material elements such as buildings, statues, memorials as well as relationships between students, lecturers, administrators and managers. Third space is thus not just a physical space but also a socio-cultural space that people occupy differently at different stages of their career (Whitchurch, 2008). Time is another critical element in the third space and for professional development practitioners; time is not punctuated by student calendar events such as exams, assessments and lectures. In fact, the university vacation is a peak period for staff development activities such as continuing development, conference attendance, scholarly writing, and projects. Professional development thus operates in a third space temporality and its temporal orientations (past, present and future) are informed by routine and habit, a capacity to contextualise current issues and challenges and to imagine creative solutions (Emirbayer \& Mische, 1998). How professional development practitioners choose to interpret the past, present and future in relation to their substantive work is connected (especially in a postcolonial country) to a particular history that influences their current work.

Third space also functions through social interactions, shared discourses and new experiences where meaning is always being negotiated and reconstructed. This 'ambivalence' refers to the ways people present themselves through different, ever-evolving cultural (self)representations in contradictory, simultaneous, and selective ways (Bhabha, 1994). This 
ambivalence of meaning is also characteristic of the postcolonial context where hybridity (Dudgeon \& Fielder, 2006) is fundamental to understanding third space realities.

'Hybrid' experiences involve a continual negotiation and creation of identities, which in turn creates a new hybrid or third culture (Bhabha, 1994). In a hybrid space, enhanced knowledge exchange is possible through questions, challenges, reinterpretations and renegotiations (Bachmann-Medick, 1996). Professional development practitioners and academic developers are well placed in the third space to introduce new discourses to challenge, debate, create and re-shape new ideas and meanings among academics. By critically reflecting on the discourses embraced, one can see how discourses are (un)consciously reproduced as well as how discourses shape the agential choices (Fairclough, 2005) and identities as professional development practitioners.

These new 'ways of being' draw on categories of academic and professional identity that transcend conventional frames. Whitchurch (2008) identifies four categories of professional identity that relate to this study: 'bounded professionals' who work within clear structural boundaries (e.g. function and job description); 'cross-boundary professionals' who actively use boundaries for strategic advantage and institutional capacity building; 'unbounded professionals' who focus on broadly-based projects and institutional development; and 'blended professionals', who work across professional and academic boundaries.

A key feature promoted by Whitchurch (2013) is the building and maintenance of relationships. Whitchurch (2013) advocates 'blended relationships' which involve partnerships rather than management; lateral teams working among senior and junior staff; less division between managers and managed; and taking on key responsibilities such as leading a project at earlier stages of careers.

The concept of third space is thus very apt to explore how academics and professionals can work together in changing educational settings (Whitchurch, 2008) to see how relational engagements (and disengagements) occur (Emirbayer \& Mische, 1998). Academic staff development or professional development is located in a liminal space between the institution's vision on the one hand and academic staff needs on the other and performs primarily an advocacy role or a servicing role or both (Quinn \& Vorster, 2012). This region of overlap or third space contains an unpredictable combination of attributes of each of the two bordering spaces (Bhabha, 1994) to enable great opportunities for participatory and collaborative practices. In this paper, the authors assert that disciplinary and mainstream teaching and learning is one place; management and administrative activities are a second place while professional and academic staff development meets in the third space. The third space is a productive and engaged space where creative and innovative practices are born that enable new academics to understand their identity, find a place of belonging and rise to their full potential; all of which have added benefits of career development and growth

\section{Methodology}

The sample for this study consisted of five participants; two were new academic lecturers (who formed part of the customised NAPP) and three were professional development practitioners (who facilitated the customised NAPP). Of the three professional development practitioners, one was appointed on professional and administrative support staff conditions of service but was functioning in an academic role. He was already working in a third space. The other two professional development practitioners were appointed on academic conditions of service but 
were involved in many activities that went beyond the traditional academic role of teaching and research. They too were already working in a third space environment even though they had not recognised it as such.

Data generated and gathered during the 2015-2016 academic year included semi-structured qualitative interviews, course materials, field notes, documents such as job descriptions and written reflective narratives. The job description documents were mapped to the activities and details of the work of each academic to look for overlap and mismatch and to establish the association between the job description and the activities these academics were involved in. This method was used to exclude and confirm whether academics were functioning in a third space environment. All five participants were interviewed using an interview schedule and the recordings were professionally transcribed for the analysis. In addition, reflective pieces were used to get in-depth information from all academics and to explore the richness that qualitative data has to offer, particularly around the identities the new academics presented and the agency they exercised during the NAPP sessions.

The authors undertook a critical discourse analysis of the interview transcriptions and reflective pieces to explore how identity and agency were being conceptualised and how these understandings were enacted in a third space of professional development. Using Fairclough's realist understanding of discourse $(2001,2005)$, we explored how discourses as mechanisms with causal powers affect the observations, experiences and events that emerged. 'Critical discourse analysis' is used here to refer to a set of ideas that have causal powers to affect social practice (Gee, 1996; Fairclough, 2000). Fairclough's (1992:64) conception of discourse as "a practice not just of representing the world, but of signifying the world, constituting and constructing the world in meaning" is critical for how new academics enter discursive spaces in higher education and make meaning of their roles and purpose. According to Kincheloe, Steinberg \& Gresson (1996: 30), "discourses as tacit rules regulate what can and cannot be said, who can speak, and who must listen, whose educational perspectives are scientific and whose are unlearned and unimportant".

To comply with ethical requirements, the academics and the professional development practitioners were briefed about the project, their participation was voluntary, and they signed consent forms, in the interest of advancing knowledge. The authors played a double role in the study; first as participants and then as researchers in this process. The research paper was conceptualised after the programme had run its course and had minimal influence on the content of the reflective pieces submitted as part of the programme. Once the primary and secondary data were collected, our roles as participants ceased and our researcher roles came into play. Despite the small sample of academics and professional development practitioners in the study, the richness of the data was evident in addressing our research question.

This is an exploratory study to look at how context affects the types of professional development work. In the section that follows, the compelling issues, insights and reflections that emerged from the data when applying a critical discourse analytical framework are discussed.

\section{Contestation over roles}

In current contexts, professional development practitioners need to be prepared to work in creative ways to mitigate traditional practices. The need for the 'tailor-made programme' in this study became necessary to address concerns of the new academics who were contesting 
the misalignment and disjuncture between their assigned roles and their own professional identities. As academics, they demonstrated they were not merely one-dimensional beings; they were important role players in their own right, based on their real identities and lived experiences and not on pre-conceived notions of the academic job or how academic spaces are traditionally occupied. In this study, it was challenging for the academics, new to their department or unit, to decipher which roles to foreground or in what order of priority in their disciplinary space. Here is where they find themselves 'between a rock and a hard place' as the title suggests. Their concerns were complicated by operational issues associated with process and bureaucracy, time on task and the contractual nature of work involving stakeholders outside the university, which can easily lead to a pervasive pessimism, as opposed to the more open-ended upbeat nature of academic work:

The academics had not had a good experience of the institution at the point when we engaged with them. There was a lot of negativity when they started (PDP 2).

Academics experienced a mismatch between operational concerns and how they were going to be assessed or appraised. When there is a clash between intended and actual outcomes, it is difficult to induct people into the institution with a sense of stability. Also, how people occupy roles is influenced by their personal projects and the resources which cannot be taken for granted. This issue was a significant discrepancy for academics as it caused them to feel a deep sense of misplacement.

My job title might say (one thing), but this is not where my strengths lie or where my interests necessary lie (Academic 2).

Third space theory asserts that people cannot be bound by traditional (job) descriptions in a university climate that, in current times, is dynamic and unpredictable. Academics and professional development practitioners' understanding of their own relationship to the past, future, and present makes a difference to how they interpret their roles and actions. There should be flexibility for newcomers to interpret their roles anew, as they experience and embed themselves in their contexts in particular ways.

We were appointed as academic lecturing staff but our duties or responsibilities were not that of the conventional academic lecturing staff (Academic 1).

Their position as 'non-conventional' academic staff meant they were unable to accrue resources in similar ways to their academic counterparts. Simultaneously, newcomers have to abide by the rules of the game for pragmatic purposes. This is characteristic of third space dynamics which often result in a process of "doublespeak" or "splitting", which involves juggling two contradictory challenges at the same time. This 'doublespeak' was evident in academics' questioning their roles:

...together with two of my other academic colleagues, we questioned the rationale of appointing us as academic/lecturers when it was known that we would be involved in operational and development work with no or minimal lecturing component (Academic 2).

\section{Blurred boundaries... blended identities}

Identity work is very much part of third space engagements and involves a process of socialisation into the practices and expectations of new academic roles. A complex set of demands related to identity formation emerges in the initial period of new academics entering 
higher education. This is when the academic typically retains their identity as a professional in a new context, for example, as an architect. This transitioning period is also when newcomers integrate the norms, practices and tools used in their larger professional community of practice with the practices of the academic community they join.

The way the reports are written meant a mind shift for me in terms of how I should be writing and conveying my message and the target audience for whom the writing is intended. This means that for operational work, descriptive writing is acceptable and when writing an academic or scholarly work, a different writing style is required (Academic 1).

The academics' professional identity, which was strongly linked to their research writing identities, constituted a major part of their professional work, which involved analysing data and writing up these analyses in reports. However, as shown above, writing in a specified genre meant different things for different academics. In this period, new academics were involved in a process of creating and shaping new identities based on their new environments that were proving to be challenging.

From their career trajectories, it became clear that the new academics in this study had already established very strong professional identities based on them being strong evaluators in their professional capacity in their distinct fields. This was sometimes at odds with their new professional contexts, which caused them considerable tension:

I think it made me realise that I like to plan and organise my work life ... that I like to know what is expected of me and by when. I do not like working under pressure with tight deadlines. Often, work is sprung on me at the last minute and this unsettles me (Academic 2).

The professional development practitioners experienced this ambivalence in their professional roles as well:

We know that people might have particular needs but I think our roles are a bit more strongly defined (in the generic NAPP). In the customised NAPP, I played a more kind of a flexible role - a role that is more of a responsive role (PDP 3 ).

The new academics in this study presented as 'bounded professionals' with clear structural boundaries regarding their roles and job descriptions, while the professional development practitioners were more 'cross-boundary professionals', who actively used boundaries for strategic advantage and institutional capacity building. Across both groups, the strongest identity invoked in the third space was that of the 'blended professionals' whose work transcended both professional and academic boundaries and domains. New academics' concept of self in this study thus faced two ways: to the professional and the academic identity within the cultural settings of the department, the institution and the national context. This 'ambivalence' is typical of third space contexts, as people present themselves differently and in selective ways.

Personal identity formation in professional settings is critical too. Not unlike professional identity, personal identity depends on a mature ability to reflect on concerns and to prioritise these concerns in one's professional life.

The values which will guide me on my way are integrity, openness, honesty, practical, being true to myself, sharing, and above all be kind to people (Academic 2). 
The assertion of a personal identity in the professional space is therefore an active and reflective process, undertaken by an active agent and, when attained, can be considered an achievement. Personal identity in the workplace is also a matter of what we care about in the world and cannot be blocked off, hidden or erased as one transitions into new professional roles and settings.

\section{Discourse of currency}

The discourse of 'currency' identified in the data is particularly interesting when one considers its links to a commodified and marketised higher education sector. At a deeper level it indicates the extent to which a neoliberal agenda has taken a firm grip on how the university sees its role in society. When new academics in this study referred to their sense of self-worth and uniqueness in terms of 'currency', the semantic associations with trade, bargaining, barter and exchange evoke important commentary on the competitive space they find themselves:

What is my currency? What is it that I have that others do not have? What is my currency worth? What makes me special? I have claimed this particular space where in the past I have not done this (Academic 2).

Going beyond job titles, self-worth involves how we embody our roles and resources and how our "signature" becomes an interpretation of who we are and what we do. However, the academics felt that their talent was not being employed by their department in ways that allowed them to use their currency optimally:

When I look at how we work or operate ... I realise many staffs' [sic] currencies are not being utilised optimally or being called upon (Academic 2).

New academics' professional 'currency' varies greatly, based on how well endowed or privileged the agent is, in terms of their academic qualifications when they enter higher education. This is also based on prior practical experience and performative achievement in a field or discipline, which accounts for a strong socially acquired concept of professional identity.

I know who I am, I know where my strengths lie, where my weaknesses are and what I should do to improve or sharpen my skills (Academic 2).

Once in the system, newcomers measure their worth by how much their professional identities influence their resourcefulness to increase their bargaining power and negotiating strength in their departments. In this study, those with stronger professional identities were in a better position to assert themselves with colleagues. For some, it was not easy:

... it was evident that the concerns that I and my colleagues had mainly resided in our perception that the department was run in a way that marginalised the expertise which we believed we had and which we thought was the reason for us to be appointed in our different positions in the first place (Academic 1).

New academics in this study felt that their social currency was being minimised or 'marginalised' based on the traditional expectations of their professional roles. They felt that more could be done to increase the social currency of their work:

From the time I started my current job in January, I have had to write reports...these reports have focused mainly on presenting and interpreting ... performance data for various stakeholders. My concern at the beginning of the NAPP was that these reports were too descriptive and template driven and that I did not find it exciting to be expected 
to write reports for different stakeholders in exactly the same way... when we could have turned them into accredited research outputs... this kind of research is crucial for the national programme's credibility and ultimate survival (Academic 1).

Through the customised NAPP, academics realised that their individual and professional 'currency' was linked to the social domain and therefore had great value in the broader social context. Professional development programmes should be sensitive to contextual issues and support newcomers in ways that increase their sense of self-worth and self-confidence, whether in professional or social ways. One of the simplest yet profound ways is through building and sustaining relationships. Academics' reflections influenced how professional development practitioners saw their roles in this third space, acknowledging that a significant feature of the 'success' of the customised NAPP was based on a set of collegial relationships between academics and professional development practitioners:

....as a professional development lecturer, l'm very interested in working with people and their ideas and their feelings and their attitudes. So, the positive shift for me... was the power of relationship building... through what we had established over the six months ... I noticed the interpersonal relationships had strengthened so much, because we offered a strong sense of support (PDP 1).

Professional development practitioners realised that strategies for navigating difficulties and hurdles must be discussed openly so more newcomers feel encouraged to assert themselves in ways that contribute to a more robust and responsive higher education workforce.

\section{The culture of conservatism}

Conservatism and innovation are diametrically positioned as critical issues for transformation of higher education currently. When new academics begin to interact in their disciplinary spaces and in their departments, they can ascertain, as novices in this space, whether the departmental and institutional culture is conservative or progressive:

I get the sense that despite the wheel being square, the establishment prefers it that way (Academic 2).

In this study, where colleagues, management and leadership, accustomed to the more traditional practices in the unit, were unable to provide cultural spaces for them to express themselves uniquely through their professional work, academics realised that the status quo may not be geared towards change and mobility but stasis:

It is this culture... that has ensured the kind of conservatism that is very stifling to those who think differently ... it occurred to me that the bigger source of this practice was a culture that has shaped the operational nature of the department for years (Academic 1).

As the new academics set about establishing their academic and professional identity at the university, they also reflected on the expectations of their line managers, heads of department and senior colleagues:

... It is this culture that I believe, informs the management of the department to treat those who are new as if they started their job in the department on a new slate ... this culture impacted negatively on the self-esteem of those who believed that they were bringing expertise and experience that would help the department grow... (Academic 1). 
This perception can lead to low self-esteem and can and constructs the university practitioner as a one-dimensional person. New academics expressed dissatisfaction with being expected to fall in line with the rest, with little consideration for unique cultural practices or the need for mentoring and support from other role players:

\begin{abstract}
My impression of XXX was that it is an excellent university - modern, advanced technology, an enabling research culture and environment. While some aspects of this are true, I was surprised that XXX is finding it hard to transform in such simple ways - shows that it is a traditional university wanting to retain the old and traditional way of doing (Academic 2).
\end{abstract}

Professional development programmes would do well to take note of different departmental cultures and work with these to enable new academics to find their feet and find their way, especially when contexts are not always conducive to embracing innovative practices that newcomers usher in.

Perhaps we think things should be done differently because we see ourselves contributing towards the growth of a department that will continue to exist in the future and that this might not be the necessary kind of thinking for people who are currently in charge of the department (Academic 1).

These tensions need to be embraced by professional development programmes as well as departmental managers and collegial units, if the university wants to retain the new academics we employ. Where there is no intrinsic connection between academics and institutional management, retention will be difficult, adding to the 'revolving door' syndrome where new academics leave as soon as they arrive due to inhospitable conditions in higher education. Third space professional development therefore must pay attention to carefully supporting new academics to ensure some level of loyalty to the institution.

\title{
10.Conclusion
}

In this paper, we reflected on a customised professional development programme for new academics who did not fit neatly into their academic roles. While their current jobs had in fact been carved out by social actors who occupied them before and incumbents entered new spaces which were conditioned by processes and people that pre-dated them (Mathieson, 2011), the study shows that traditional jobs can be interpreted anew. Even though, as the title suggests, it is a difficult place to be 'between a rock and a hard place', there are opportunities for new academics, as in this study, to create positive outcomes by displaying a considerable level of perseverance in their efforts to develop their personal concerns into useful projects.

Issues of identity emerged in the hybrid space between academics' assigned roles and self-interpreted roles that raised tensions and concerns between traditional and innovative practices and identities in the academy. It was evident that all four identity categories identified by Whitchurch (2008) in the third space were present and overlapped in varying degrees across academics and professional development practitioners' identities. Through the intense identity work, they had to do as new academics, to concretise their goals and address their needs as newcomers, academics reflected richly on their understanding of their professional, academic and social identity (Archer, 2000). These dialogic activities enabled shifts from assumptions to reflections (Carrillo, 2000). The data showed that activities and experiences enabled in the third space involved them challenging assumptions, learning reciprocally and creating new ideas, which emerged through negotiation, co-creation of identities, relationships and through multi-voiced discussions across differences (Muller \& Druin, 2012). 
This study also highlights the need for higher education to be aware of the diverse backgrounds of new academics and what the university needs to do to offer them a soft landing. Professional development programmes especially need to be re-conceptualised and re-contextualised in terms of how they support new people through the initial transitions and to reflect on whether traditional professional development methods and perspectives still have purchase in a higher education environment that is now so complex and dynamic. Understanding the affordances of third spaces can create generative spaces where professional development practitioners can harness the potential for authentic interaction that can lead to an expanded form of learning and the development of new knowledge that is transformative (Gutiérrez et al., 1995). These insights are valuable for professional development in terms of how the university relates to and engages with issues that fall outside the ambit of the traditional induction curriculum model.

\section{References}

Archer, M.S. 2000. Being human. The problem of agency. Cambridge: University Press. https://doi.org/10.1017/CBO9780511488733

Bachmann-Medick, D. 1996. Cultural misunderstanding in translation: Multicultural coexistence and multicultural conceptions of world literature. Erfurt Electronic Studies in English, 7, 7-96.

Ball, S.J. 2012. Global education Inc. New policy networks and the neo-liberal imaginary. London: Routledge.

Barnett, R. 2000. Supercomplexity and the curriculum. Studies in Higher Education, 253, 255-265. https://doi.org/10.1080/713696156

Bassnett, S. 2005. The importance of professional university administration: A perspective from a senior university manager. Perspectives, 9, 98-102.

Beck, J. \& Young, M.F.D. 2005. The assault on the professions and the restructuring of academic and professional identities: A Bernsteinian analysis, British Journal of the Sociology of Education, 262, 183-197. https://doi.org/10.1080/0142569042000294165

Behari-Leak, K. 2017. New academics, new higher education contexts: A critical perspective on professional development. Teaching in Higher Education, 22, 5, 485-500. https://doi.org/1 0.1080/13562517.2016.1273215

Bhabha, H.K. 1990. "The third space: Interview with Homi Bhabha”. In J. Rutherford (Ed.). Identity: Community, culture and difference. London: Lawrence and Wishart.

Bhabha, H.K. 1994. The location of culture. London: Routledge.

Boyd, P. 2010. Academic induction for professional educators: Supporting the workplace learning of newly appointed lecturers in teacher and nurse education. International Journal for Academic Development, 152, 155-165. https://doi.org/10.1080/13601441003738368

Brandt, E. \& Messeter, J. 2004. "Facilitating collaboration through design games", in A Bond, A. Clement, $\mathrm{F}$ de Cindio, D Schuler \& $\mathrm{P}$ van den Besselaar (Eds.). Proceedings of the 8th conference on Participatory design: Artful integration: Interweaving media, materials and practice - Volume 1, Toronto, Canada, July 27-31, 2004, pp. 121-131.

Brookfield, S. 1995. The getting of wisdom: What critically reflective teaching is and why it's important. Becoming a critically reflective teacher, 1-28. 
Cain, J. \& Hewitt, J. 2004. Off course. From public place to marketplace at Melbourne University. Melbourne: Scribe Publications.

Carrillo, R. 2000. Intersections of official script and learners' script in third space: A case study on Latino families in an after-school computer program. In B. Fishman \& S. O'ConnorDivelbiss (Eds.). Proceedings of the Fourth International Conference of the Learning Sciences (pp. 312-313). Mahwah, NJ, 14-17 July.

Clegg, S. 2008. Academic identities under threat? British Educational Research Journal, 343, 329-345. https://doi.org/10.1080/01411920701532269

Connors, B. 2012. Emergent aspects of pedagogy in higher education in England: A critical realist study. Paper presented at the 15th International Association for Critical Realism (IACR) Conference, Rhodes University, Grahamstown, 18-20 July.

Deem, R. \& Brehony, K. 2005. Management as ideology: The case of 'new managerialism' in higher education. Oxford Review of Education, 31, 217-235. https://doi. org/10.1080/03054980500117827

Dudgeon, P. \& Fielder, J. 2006. Third spaces within tertiary places: Indigenous Australian studies. Journal of Community and Applied Social Psychology, 165, 396-409. https://doi. org/10.1002/casp.883

Emirbayer, M. \& Mische, A. 1998. What is agency? American Journal of Sociology, 1034, 962-1023. https://doi.org/10.1086/231294

Fairclough, N. 1992. Discourse and social change. Cambridge: Polity Press.

Fairclough, N. 2000. Discourse, social theory and social research: The discourse of welfare reform. Journal of Sociolinguistics, 4(2), 163-195. https://doi.org/10.1111/1467-9481.00110

Fairclough, N. 2005. Peripheral vision: Discourse analysis in organization studies: The case for critical realism. Organization Studies, 26(6), 915-939. https://doi. org/10.1177/0170840605054610

Gee, J., Hull, G. \& Lankshear, C. 1996. The new work order: Behind the language of the new capitalism. St Leonards: Allen \& Unwin.

Gutiérrez, K.D., Rymes, B. \& Larson, J. 1995. Script, counterscript, and underlife in the classroom: James Brown versus Brown v. Board of Education. Harvard Educational Review, 653, 445-471. https://doi.org/10.17763/haer.65.3.r16146n25h4mh384

Henkel, M. 2000. Academic identity and autonomy revisited. In I. Bleiklie \& M. Henkel (Eds.). Governing knowledge: A study of continuity and change in higher education. New York: Springer.

HESA. 2011. A generation of growth: Proposal for a national programme to develop the next generation of academics for South African higher education. Pretoria: University of South Africa.

Kincheloe, J.L., Steinberg, S.R. \& Gresson, A.D. 1996. Measured lies: The bell curve examined. New York: St. Martin's Press.

Leibowitz, B., Bozalek, V., Van Schalkwyk, S. \& Winberg, C. 2014. Institutional context matters: The professional development of academics as teachers in South African higher education. Higher Education, 692, 315-330. 
Mathieson, S. 2011. Developing academic agency through critical reflection: A sociocultural approach to academic induction programmes. International Journal for Academic Development, 163, 243-256. https://doi.org/10.1080/1360144X.2011.596730

Muller, M.J. \& Druin, A. 2012. Participatory design - the third space in human-computer interaction. In J.A. Jacko (Ed.). Human - Computer interaction handbook fundamentals, evolving technologies, and emerging applications 3rd edition. Florida1: CRC Press.

Quinn, L. \& Vorster, J. 2012. Training new academics is a complex challenge. Available at http://mg.co.za/article/2012-10-05-00-training-new-academics-is-acomplex-challenge [Accessed 05 Oct 2012 00:00]

Reay, D. 2004. Cultural capitalists and academic habitus: Classed and gendered labour in UK higher education. Women's Studies International Forum, 271, 31-39. https://doi.org/10.1016/j. wsif.2003.12.006

Saudelli, M. 2012. Unveiling third space: A case study of international educators in Dubai, United Arab Emirates. Canadian Journal of Education 35(3), 101-116.

Soja, E.J. 1989. Postmodern geographies: The reassertion of space in critical social theory. London: Verso.

Szekeres, J. 2004. The invisible workers. Journal of Higher Education Policy and Management, 22, 7-22. https://doi.org/10.1080/1360080042000182500

Trowler, P. \& Knight, P.T. 2000. Coming to know in higher education: Theorising faculty entry to new work contexts. Higher Education Research and Development, 191, 27-42. https://doi. org/10.1080/07294360050020453

Whitchurch, C. 2008. Shifting identities and blurring boundaries: the emergence of third space professionals in UK higher education, Higher Education Quarterly, 624,377-396. https://doi. org/10.1111/j.1468-2273.2008.00387.x

Whitchurch, C. 2013. Reconstructing identities in higher education. London: Routledge. 